\title{
Um Estudo sobre Bullying entre Escolares do Ensino Fundamental
}

\section{A Study on Bullying Victimization among Peers in Elementary and Junior High School}

\author{
Marcos Vinicius Francisco*,a,b \& Renata Maria Coimbra Libório ${ }^{a, c}$ \\ ${ }^{a}$ Universidade Estadual Paulista Júlio de Mesquita Filho \\ ${ }^{b}$ Secretaria de Estado da Educação de São Paulo \& ${ }^{c}$ Dalshousie University
}

\begin{abstract}
Resumo
A presente pesquisa, de natureza quali-quantitativa, teve como objetivo caracterizar o bullying em duas escolas públicas estaduais de Presidente Prudente-SP, através da aplicação de questionários semi-aberto, em duzentos e oitenta e três alunos de $5^{\text {as }}$ e $8^{\text {as }}$ séries, quanto à: freqüência, gênero, local e idades prevalecentes de acometimento do bullying, tipos, local de residência do aluno, efeitos sobre o comportamento e sentimentos do vitimizado, e opiniões dos participantes sobre o enfrentamento do problema. O questionário utilizado baseou-se em estudos de Elliott (1992) e Olweus (1991). Os resultados permitiram caracterizar as dimensões do bullying na realidade estudada, bem como constatar sua presença no ambiente escolar, o que requer mais atenção dos profissionais da educação para o enfrentamento do fenômeno.

Palavras-chave: Bullying; violência; escolares.
\end{abstract}

\begin{abstract}
This research, of quali-quantitative nature, had the aim of characterizing the phenomenon of bullying in two state public schools of Presidente Prudente-SP through the use of questionnaires applied to two hundred eighty-three students of $5^{\text {th }}$ and $8^{\text {th }}$ grades. It was taken into consideration frequency, gender, most common places and ages of bullying prevalence, students' place of living, effects on the behavior and the feelings of the victim, as well as the opinion of the participants about facing the problem. The questionnaire used was based on studies of Elliot (1992) and Olweus (1991). The results were likely to characterize the dimensions of bullying in the studied reality, what allowed us to confirm its presence in the school environment, requesting more attention from the education professionals concerning the phenomenon.

Keywords: Bullying; violence; students.
\end{abstract}

A escola, multifacetada, vem presenciando situações de violência que estão tomando proporções assustadoras em nossa sociedade. As situações de violência, anteriormente esporádicas, se tornaram uma constante em nossos dias.

Fante $(2003,2005)$ aponta que a violência escolar nas últimas décadas adquiriu crescente dimensão em todas as sociedades. O que a torna questão preocupante é a grande incidência de sua manifestação em todos os níveis de escolaridade. Nesse contexto, vários estudos e pesquisas vêm sendo desenvolvidos com o intuito de contribuir para que a violência seja extirpada ou minimizada, não somente no ambiente escolar, mas em todas as esferas de relacionamentos sociais (Abramovay, 2003; Debarbieux \& Blaya, 2002; Ortega \& Del Rey, 2002).

Entretanto, uma forma de violência que vem ganhando destaque por meio dos estudos acadêmicos é o bullying, especialmente em alguns países. Conforme Almeida, Lisboa e Caurcel (2007), Lopes Neto (2005) e Pizarro e Jiménez (2007) tal violência ocorre através da perseguição e inti-

* Endereço para correspondência: Faculdade de Ciência e Tecnologia - UNESP, Departamento de Educação Roberto Simonsen, 305, Jardim das Rosas, Presidente Prudente/SP, Brasil, CEP 19060-900. E-mail: marcos_educa01@yahoo.com.br midação de um aluno por um ou vários colegas, com a intenção clara de provocar-lhe sofrimentos e apresenta caráter repetitivo e intencional. Vários sinônimos têm sido utilizados em português para fazer referência ao tema, visto que não há uma palavra em nosso vocabulário que consiga dar conta completamente da terminologia, maus tratos, vitimização, intimidação, agressividade e violência entre pares (Almeida et al., 2007; Lopes Neto, 2005; Pereira, 2002).

Almeida et al. (2007) explicam que:

os maus tratos se distinguem de outras formas de agressão por seu caráter repetitivo ou sistemático, pela intenção de causar danos ou prejudicar alguém; que é habitualmente percebido/a como mais fraco/a ou está em uma posição fragilizada e dificilmente pode se defender. A recorrência, a intencionalidade e a assimetria caracterizam as situações de agressão como abuso de poder, no entanto, também pode acrescentar-se que estes comportamentos e atitudes não são necessariamente provocados pelas vítimas. (p. 108).

Sabe-se que o bullying é um tema muito discutido na Noruega (Olweus, 1991), Portugal (Almeida et al., 2007; Freire, Simão, \& Ferreira, 2006; Pereira, 2002), Espanha (Ramírez, 2001) e nos Estados Unidos (Valles, 2007). 
No Brasil, o interesse pelo estudo do bullying é mais recente, requerendo esforços para que se possa compreendê-lo e propor intervenções mais articuladas com a realidade do país. Como importantes referências, vale mencionar Fante $(2003,2005)$ que realizou estudos de caracterização de bullying em cidades do interior do estado de São Paulo-SP e Lopes Neto (2005) que junto da Associação Brasileira de Proteção à Infância e à Adolescência (ABRAPIA), desenvolveu o Programa de Redução do Comportamento Agressivo entre Estudantes, com mais de 5.500 alunos de $5^{\text {as }}$ a $8^{\text {as }}$ séries do Ensino Fundamental, na cidade do Rio de Janeiro-RJ, ao investigar as características de tais atos, além de sistematizar estratégias para intervir e reduzir a agressividade entre os escolares; Mascarenhas (2006) que trabalhou com uma amostra de 300 sujeitos de diferentes turmas de Ensino Fundamental e Médio, Educação de Jovens e Adultos, além de professores, em uma investigação-ação na zona urbana de Porto Velho-RO, e que apontou à necessidade de medidas preventivas frente à gestão institucional do bullying e da indisciplina.

No que tange a saúde emocional e o bem-estar de discentes e docentes na esfera escolar, Palácios e Rego (2006) fizeram uma análise da literatura, com o objetivo de apontar o bullying não como um mero problema estudantil, mas como um fenômeno no qual a relação entre professores e alunos deve ser considerada.

Conforme Fante (2003, 2005) e Lopes Neto (2005) os praticantes do bullying são conhecidos como autores agressores. Os alvos, as pessoas vitimizadas, geralmente sofrem as consequiências do bullying e, na maioria das vezes são descritas como pouco sociáveis, inseguras, possuindo baixa auto-estima, quietas e que não reagem efetivamente aos atos de agressividade sofridos. De acordo com Lopes Neto (2005), Pizarro e Jiménez (2007) e Ramírez (2001) as testemunhas não participam diretamente em atos de bullying e geralmente se calam, por receio de tornarem-se as próximas vítimas.

Para Tognetta (2005), neste contexto de causadores e vítimas de bullying, ambos precisam de ajuda. Por um lado, as vítimas sofrem uma deterioração da sua auto-estima, e do conceito que tem de si, por outro, os agressores também precisam de auxílio, visto que sofrem grave deterioração de sua escala de valores e, portanto, de seu desenvolvimento afetivo e moral.

Apesar da dimensão e das conseqüências, este problema tem sido socialmente negligenciado, já que muitos adultos consideram-no inevitável na vida escolar e, por vezes, encaram-no como algo que faz parte da iniciação à vida adulta (Freire et al., 2006; Lopes Neto, 2005; Mascarenhas, 2006; Pizarro \& Jiménez, 2007). A intimidação e a vitimização são processos de grande complexidade que se produzem no marco das relações sociais e com frequiência no meio escolar, podendo agravar progressivamente o problema com severas repercussões a médio e longo prazos para os implicados.

Nesse sentido, o objetivo dessa pesquisa foi caracterizar o bullying em duas escolas públicas estaduais de Presiden- te Prudente-SP, através da aplicação de questionários, em duzentos e oitenta e três alunos de $5^{\text {as }}$ e $8^{\text {as }}$ séries, em termos de: freqüência, gênero do/a agressor/a e vitimizado/a, local e idades mais frequientes de acometimento do bullying, tipos (físico ou verbal), local de residência do aluno (próximo ou distante da escola), efeitos sobre o comportamento e sentimentos do/a vitimizado/a, e opiniões dos participantes da pesquisa sobre o enfrentamento do problema.

\section{Método}

\section{Seleção das Escolas}

A seleção das duas escolas que participaram da pesquisa fundamentou-se em um dos objetivos: analisar a influência do tipo de vinculação escolar e local de moradia do sujeito nos episódios do bullying. Pretendeu-se avaliar se o fato da criança ou adolescente residir no mesmo bairro da escola freqüentada, maximizava ou minimizava a ocorrência do bullying entre escolares.

Uma das escolas localiza-se na região periférica da cidade. Tal seleção justifica-se pelo fato dos alunos viverem em um mesmo bairro e conviverem além dos muros escolares. A segunda instituição localiza-se no centro da cidade e atende alunos de diversos bairros, os quais se encontram e se relacionam basicamente durante o período escolar.

A partir da seleção das duas escolas, solicitou-se à Diretoria Regional de Ensino a informação sobre o número de classes de $5^{\text {as }}$ e $8^{\text {as }}$ séries existentes em tais instituições, sendo que cada uma possuía 6 turmas por série, perfazendo um total de 24 turmas. Com base nesses dados, adotouse a amostragem por conglomerado, pois ela permite que a população em estudo possa ser dividida em pequenos grupos, chamados de conglomerados, no caso dessa pesquisa as séries selecionadas.

Dos 24 conglomerados resultantes fez-se necessário a redução para 12 , o que equivale a três $5^{\text {as }}$ e três $8^{\text {as }}$ séries de cada unidade escolar, e representa aproximadamente 50\% da população total de alunos dessas séries nessas instituições. Tal redução viabilizou a realização da pesquisa, ao passo que permitiu aos pesquisadores um envolvimento efetivo em todas as etapas do processo de aplicação de questionários.

No que se refere à escola localizada na região periférica da cidade, dos 110 alunos das $5^{\text {as }}$ séries pertencentes aos conglomerados pesquisados, 83 responderam aos questionários e dos 110 alunos das $8^{\text {as }}$ séries, 82 participaram, o que totaliza $75,00 \%$ dos alunos das turmas selecionadas. Na escola da região central, dos 75 alunos das $5^{\text {as }}$ séries, 47 participaram e dos 99 alunos das $8^{\text {as }}$ séries, 71 responderam aos questionários, o que equivale a $67,82 \%$ dos conglomerados pesquisados nessa escola. Sendo assim, nossa amostra total de participantes efetivos constituiu-se de 283 sujeitos.

Fante (2005) aponta que em tais séries ocorrem os maiores incidentes de bullying. Vale destacar que alguns trabalhos em âmbito internacional também utilizaram a mesma faixa etária, estabelecida para a amostra da presente pesquisa (Pizarro \& Jiménez, 2007; Ramírez, 2001). 


\section{Participantes}

De acordo com os dados mencionados, a pesquisa foi realizada com 283 sujeitos, alunos das duas escolas públicas selecionadas da rede estadual de ensino do município de Presidente Prudente-SP, no ano de 2006, com autorização da Dirigente Regional de Ensino para o seu desenvolvimento. Destes, 43,46\% estavam na faixa etária de 10 a 12 anos; 49,46\% de 13 a 15 anos; 6,36\% de 16 a 18 anos. Apenas dois sujeitos, que representam 0,70\% deixaram de informar suas idades. A idade média da amostra foi de 12,82 anos.

\section{Instrumentos}

O questionário aplicado à amostra constou de 28 questões de múltipla escolha e duas questões abertas. Baseouse em estudos de Elliott (1992) e Olweus (1991), a partir dos quais foram feitas adaptações para a presente pesquisa, com a introdução das questões abertas, e tradução de sua versão para o português. Na ampliação do instrumento readequaram-se alguns termos de difícil entendimento para o nosso contexto, como por exemplo, a substituição de bullying para "maus tratos entre escolares". Vale apontar que alguns autores de Portugal e Costa Rica utilizam denominação semelhante, com pequena variação, "maus tratos entre iguais" (Almeida et al., 2007; Pizarro \& Jiménez, 2007). Além disso, buscou-se entender se há alguma relação entre o local de moradia dos alunos com a escola e a ocorrência de bullying, bem como, a idade dos agressores e a freqüência de maus tratos que os alunos haviam presenciado na escola. Com relação às questões abertas procurou-se identificar a opinião dos participantes sobre as formas de enfrentamento dos maus tratos.

Destarte, o questionário ficou subdividido em quatro partes, sendo que a primeira visava à identificação do perfil do entrevistado, a segunda apresentava questões sobre ser maltratado por outro na escola, a terceira apresentava teor relacionado aos maus tratos que os alunos haviam presenciado na escola desde o ano anterior e, por último, as questões estavam relacionadas a maltratar outros colegas na escola.

\section{Procedimentos}

Antes do início da pesquisa de campo, o projeto foi submetido para avaliação junto ao Comitê de Ética em Pesquisa da Faculdade de Ciências e Tecnologia (FCT)/ Universidade Estadual Paulista Júlio de Mesquita Filho (UNESP), Campus de Presidente Prudente-SP, obtendo um parecer favorável para sua realização.

Para efetuar a coleta de dados, inicialmente entrou-se em contato com as diretoras das escolas selecionadas com a finalidade de solicitar autorização para aplicação dos questionários e seleção das seis turmas de cada escola. Posteriormente estabeleceu-se um primeiro contato com as turmas selecionadas, no qual os estudantes foram convidados a participar da pesquisa. Foi entregue para cada um dos alunos o Termo de Consentimento Livre e Esclarecido (TCLE), e explicou-se que deveriam ser lidos e assinados por seus pais ou responsáveis, no caso de consentirem a participação de seus filhos/as na pesquisa. Nesse sentido, do total de alunos da escola localizada na área central e periférica da cidade, constatou-se respectivamente que $26,43 \%$ e $17,72 \%$ faltaram no dia da aplicação dos questionários; $5,17 \%$ e 5,90\% não quiseram participar; $0,56 \%$ e $1,37 \%$ não foram autorizados por seus pais ou responsáveis.

Durante o processo de aplicação dos questionários houve apenas um encontro com cada turma, com duração média de aproximadamente duas horas. Mesmo sendo assegurada confidencialidade as informações coletadas, no período em que os pesquisadores estavam com os alunos solicitou-se aos professores que se retirassem das salas, para que os participantes pudessem sentir-se mais a vontade. Foram aplicados questionários em 283 alunos de três $5^{\text {as }} \mathrm{e}$ três $8^{\text {as }}$ séries de cada escola, para garantir maior visibilidade e generalidade aos resultados da pesquisa.

A natureza dos dados é quali-quantitativa. Adotou-se tal método por acreditar que pesquisas desse porte possibilitam uma articulação e ampliação a partir de uma visão na qual se realiza uma real combinação entre aspectos qualitativos e quantitativos (Gouveia, 1984; Thiollent, 1984). Os dados, após sua coleta, foram submetidos ao teste estatístico no software SPSS, versão 12.0. A análise foi realizada com base em tabelas de distribuição de freqüência, sendo aplicado o Teste Qui-quadrado para testar associação entre as variáveis consideradas, de acordo com as respostas obtidas através dos questionários.

\section{Resultados e Discussão}

Mais da metade dos alunos da escola localizada na região periférica de Presidente Prudente-SP moravam perto dela $(50,30 \%)$, e $13,30 \%$ longe, mas iam a pé até ela, gastando menos de dez minutos para deslocar-se à instituição. Na escola da área central, 90,70\% moravam longe da escola freqüentada.

Sobre a existência de maus-tratos na escola (Tabela 1), constatou-se que embora $41,50 \%$ dos entrevistados da pesquisa disseram nunca terem sido maltratados na escola, outros $23,30 \%$ dos participantes apontaram ter sofrido ameaças.

Nas $5^{\text {as }}$ séries, as formas de violência se manifestaram mais por meio de ameaças físicas, contudo, nas $8^{\text {as }}$ séries destacaram-se os insultos e provocações. Entretanto, em seus estudos, Martins (2005) constatou que a agressão indireta é a forma mais utilizada para se maltratar os pares nessa faixa etária. Percebe-se que de uma série para outra houve um decréscimo no número de alunos que afirmaram não terem sido maltratados na escola, o que leva a conclusão de que o tempo pode modificar a expressividade do bullying.

Através do teste estatístico Qui-quadrado, pode-se verificar que as $5^{\text {as }}$ e $8^{\text {as }}$ séries das escolas localizadas na região central e periférica não diferem estatisticamente, ou seja, a freqüência das formas de maus tratos em ambas as escolas são significativamente iguais nas mesmas séries, com $p$-valor de 0,228 para as $5^{\text {as }}$ séries e $p$-valor de 0,130 para as $8^{\text {as }}$ séries. 
Francisco, M. V. \& Libório, R. M. C. (2009). Um Estudo sobre Bullying entre Escolares do Ensino Fundamental.

Tabela 1

Tipos ou Formas de Maus Tratos na Escola

\begin{tabular}{ll}
\hline & Formas de maus tratos na escola \\
\hline $5^{\text {as }}$ séries escola da região periférica & "fui ameaçado" \\
& $36,40 \%$ \\
$5^{\text {as }}$ séries escola da região central & "fui ameaçado" \\
& $26,50 \%$ \\
$8^{\text {as }}$ séries escola da região periférica & "xingaram-me, insultaram-me ou riram de mim" \\
& $21,40 \%$ \\
$8^{\text {as }}$ séries escola da região central & "xingaram-me, insultaram-me ou riram de mim" \\
& $18,90 \%$ \\
Ambas as escolas & "fui ameaçado" \\
& $23,30 \%$ \\
\hline
\end{tabular}

Nota. Fonte: Pesquisa de Campo, 2006 - Nível de significância $<0,05$.

Com relação à caracterização da freqüência e duração dos maus tratos (Tabela 2), é que se identificaram as vítimas de bullying, sendo que para caracterizá-las como tal, consideraram-se todos aqueles que apontaram a duração dos seus maus tratos nas seguintes respostas: duraram várias semanas; têm-se mantido durante todo esse ano; e têm-se mantido há vários anos, fazendo o cruzamento das mesmas com as seguintes escalas de frequiência: de três a seis vezes ao ano; uma vez por semana; e várias vezes por semana.

Segundo Pereira (2002) e Pizarro e Jiménez (2007) para um indivíduo ser caracterizado como vítima é necessário que o mesmo tenha sofrido de três a seis ataques no mínimo, em um mesmo período do ano, e que estes ataques apresentem um caráter de intencionalidade e repetição.

Nas $5^{\text {as }}$ séries da escola da região periférica, $17,00 \%$ dos alunos encaixaram-se no perfil de vítimas, enquanto que nas $5^{\text {as }}$ séries da escola da região central esse número equivale a $12,80 \%$. Já nas $8^{\text {as }}$ séries das escolas das regiões periférica e central, $14,90 \%$ e $15,40 \%$ respectivamente, apresentaram características típicas de vítimas do bullying. No geral, esse número perfaz a $13,90 \%$ dos participantes da pesquisa.

Ao aplicar o teste Qui-quadrado pode-se concluir que não há diferenças significativas entre as $5^{\text {as }}$ séries das escolas localizadas na região periférica e central quanto à vitimização de bullying, com $p$-valor de 0,40 . As $8^{\text {as }}$ séries de ambas as escolas apresentaram freqüências abaixo de 5, logo em vez de se utilizar o teste Qui-quadrado, fez-se o uso do teste exato de Fisher que permite o seu cálculo quando mais que $20 \%$ das freqüências apresentadas em tabelas de contingências são menores que 5 , pois produz um erro menor que o teste Qui-quadrado para estes casos. Desse modo, o teste exato de Fisher apresentou $p$-valor igual a 0,35 , indicando não haver diferenças entre as $8^{\text {as }}$ séries de ambas as escolas.

Freire et al. (2006) ao fazerem uma comparação dos resultados de envolvidos com bullying em seus estudos, chegaram à conclusão que 7,00\% dos alunos estavam atuando como vítimas ou agressores, entretanto elucidam o fato de outros estudos internacionais apresentarem índices que variam de 7,00\% a 21,00\%. Lopes Neto (2005) e Pizarro e
Jiménez (2007) contrapõem tais dados, ao indicar que a prevalência de vitimizados varia de $8,00 \%$ a $46,00 \%$, e de agressores, de $5,00 \%$ a $30,00 \%$. Os resultados obtidos no presente estudo, no que tange ao número de vitimizados vão ao encontro dos dados constatados nas pesquisas de Lopes Neto (2005) e Pizarro e Jiménez (2007), no entanto, em desacordo com os resultados apresentados por Freire et al. (2006).

Outro ponto a ser destacado é que, na média geral, não há diferenças significativas entre os índices encontrados na escola localizada na região periférica, se comparados aos encontrados na escola da região central da cidade. Sendo assim, tais dados sugerem mais estudos, no que se refere à articulação que pode haver entre bullying e local de moradia.

Ao analisar os locais nos quais os alunos mais sofreram maus tratos (Tabela 2), observa-se que nas $5^{\text {as }}$ séries das duas escolas predominaram as respostas dos que apontaram os recreios como lugar ideal para os agressores fazerem as suas vítimas, sendo $38,60 \%$ e $32,70 \%$, respectivamente, para os alunos das escolas localizadas na região periférica e central. Entre os alunos das $8^{\text {as }}$ séries de ambas as escolas, destacaram-se as respostas dos que disseram que os maus tratos ocorreram na própria sala de aula, sendo a percentagem de $29,80 \%$ para a escola da área periférica e $23,00 \%$ na escola da região central. O teste Qui-quadrado aplicado em ambas às séries não demonstrou diferenças significativas entre as $5^{\text {as }}$ séries que apresentaram $p$-valor de 0,47 e de 0,34 para as $8^{\text {as }}$ séries.

No geral, as respostas mais lembradas pelos participantes da pesquisa foram os recreios $(28,60 \%)$, seguido das salas de aula, com um percentual de $27,90 \%$. Salientase que nos pátios e nas salas de aula, por mais que haja funcionários e professores, o bullying ocorre de forma camuflada em várias situações, o que dificulta intervenções, principalmente quando o profissional em questão naturaliza tais situações.

Em seus estudos, Fante (2005) e Lopes Neto (2005) constataram que as condutas de bullying foram praticadas com maior intensidade nas salas de aula. Entretanto, Pereira (2002) debruçou suas atenções para os momentos de recreio, visto a alta intensidade com que o bullying se ma- 
Tabela 2

Vitimas e Locais de Incidência do Bullying

\begin{tabular}{lccc}
\hline & $\begin{array}{c}\text { Sofreram algum tipo } \\
\text { de violência }\end{array}$ & $\begin{array}{c}\text { Vítimas de bullying } \\
\text { Local onde o bullying } \\
\text { mais ocorreu }\end{array}$ & $\begin{array}{c}\text { recreios }(38,60 \%) \\
\text { recreios }(32,70 \%) \\
\text { 5as }\end{array}$ \\
$5^{\text {as }}$ séries escola da região periférica & $67,00 \%$ & $17,00 \%$ & sala de aula $(29,80 \%)$ \\
$8^{\text {as }}$ séries escola da região central & $63,30 \%$ & $12,80 \%$ & sala de aula $(23,00 \%)$ \\
$8^{\text {as }}$ séries escola da região central & $57,10 \%$ & $14,90 \%$ & recreios $(28,60 \%)$ \\
Ambas as escolas & $49,30 \%$ & $15,40 \%$ & $13,90 \%$ \\
\hline
\end{tabular}

Nota. Fonte: Pesquisa de Campo, 2006 - Nível de significância < 0,05.

nifestava nestes lugares nas escolas portuguesas. Vale ainda apontar que Pizarro e Jiménez (2007) identificaram o próprio bairro como local de maior incidência, seguido por ambientes do espaço escolar.

Ao analisar a variável gênero do agressor e vitimizado (Tabela 3) percebe-se que entre as $5^{\text {as }}$ séries das escolas localizadas na área central e periférica, respectivamente, $14,90 \%$ e $20,20 \%$ dos meninos afirmaram ser agredidos só por meninos. Para verificar se há diferença significativa entre essas freqüências foi calculado o teste de Qui-quadrado, obtendo-se o p-valor de 0,34 , ou seja, estatisticamente não há diferença significativa entre as $5^{\text {as }}$ séries de ambas as escolas. Para as meninas, a mesma tabela apresenta que $13,10 \%$ das $5^{\text {as }}$ séries da escola localizada na região periférica e $10,60 \%$ da escola da área central afirmaram ser agredidas tanto por meninos como por meninas. O teste Qui-quadrado apontou um $p$-valor de 0,72 , também não apresentando diferenças significativas.

Tabela 3

Gênero dos Agressores e dos Vitimizados

\begin{tabular}{|c|c|c|}
\hline & Meninos & Meninas \\
\hline \multirow[t]{2}{*}{$5^{\text {as }}$ séries escola da região periférica } & $20,20 \%$ & $13,10 \%$ \\
\hline & só por meninos & tanto por meninos e meninas \\
\hline \multirow[t]{2}{*}{$5^{\text {as }}$ séries escola da região central } & $14,90 \%$ & $10,60 \%$ \\
\hline & só por meninos & tanto por meninos e meninas \\
\hline \multirow[t]{2}{*}{$8^{\text {as }}$ séries escola da região periférica } & $18,50 \%$ & $12,30 \%$ \\
\hline & só por meninos & só por meninos \\
\hline \multirow[t]{2}{*}{$8^{\text {as }}$ séries escola da região central } & $9,90 \%$ & $12,70 \%$ \\
\hline & só por meninos & só por meninos \\
\hline \multirow[t]{2}{*}{ ambas as escolas } & $16,30 \%$ & $10,20 \%$ \\
\hline & só por meninos & tanto por meninos e meninas \\
\hline
\end{tabular}

Nota. Fonte: Pesquisa de Campo, 2006 - Nível de significância < 0,05.

Quanto aos sentimentos que experimentam as vítimas após os maus tratos na escola (Tabela 4), a resposta que mais incidiu foi "eu me senti triste", sendo $34,10 \%$ nas $5^{\text {as }}$ séries da escola da região periférica e $26,50 \%$ nas $5^{\text {as }}$ séries da escola da área central. Entre os alunos das $8^{\text {as }}$ séries prevaleceu a resposta "eu me senti mal" $(29,60 \%)$; "eu me senti triste" $(22,30 \%)$ e "eu fiquei preocupado com o que os outros podiam pensar de mim" $(17,80 \%)$. Os alunos mais
Nas $8^{\text {as }}$ séries, $18,50 \%$ dos meninos da escola localizada na região periférica e $9,90 \%$ da escola da área central afirmaram ser agredidos só por meninos. O teste Qui-quadrado constatou que não há diferença estatística significativa, com $p$-valor de 0,07. Para as meninas das $8^{\text {as }}$ das escolas da região periférica e central, respectivamente, $12,30 \%$ e $12,70 \%$ afirmaram terem sido agredidas só por meninos. O teste Qui-quadrado para essas freqüências apresentou $p$-valor igual a 0,87 , ou seja, não há diferença significativa.

Em contrapartida, Gomes et al. (2007) ao fazerem uma análise da literatura sobre vários estudos referentes ao bullying, chegaram à conclusão de que os meninos costumam ser mais agredidos somente por meninos, enquanto que as meninas são agredidas tanto por meninas quanto por meninos. Contudo, não se pode deixar de refletir que as meninas podem apresentar formas mais sutis de expressar a violência, e que muitas vezes os meninos são movidos por processos culturais e de socialização que os encorajam a assumir posições violentas rotineiramente naturalizadas pela sociedade. velhos demonstraram maior preocupação quanto à avaliação que as outras pessoas poderiam fazer deles. Com relação às freqüências dos sentimentos que experimentaram as vítimas de bullying, o teste Qui-quadrado apontou um $p$-valor de 0,35 e 0,86 , respectivamente para as $5^{\text {as }}$ e $8^{\text {as }}$ séries das escolas localizadas na região periférica e central, ou seja, não há diferenças significativas entre as freqüências de ambas as escolas. 
Francisco, M. V. \& Libório, R. M. C. (2009). Um Estudo sobre Bullying entre Escolares do Ensino Fundamental.

Martins (2005) constatou que a maioria das vítimas não se sente bem na escola, dado que conforme a autora é congruente com o fato da vitimização ocorrer no contexto escolar. Nesse sentido, Tognetta (2005) afirma que a vítima não pressupõe outras formas de resolver o problema a não ser ficar quieto, ou introverter-se em sua própria condição, além de não possuir status para reagir, ou ao menos se defender expressando o que sente de forma concisa. Entretanto, autores como Donnon e Hammond (2007) vêm discutindo sobre as diferenças nas formas de reação de adolescentes e jovens frente ao bullying, indicando que alguns conseguem enfrentar mais satisfatoriamente tal situação adversa e demonstrando que o mesmo não afeta tão negativamente suas vidas.

Tabela 4

Sentimentos que Experimentaram as Vitimas de Bullying

Sentimentos experimentados por vítimas de bullying

\begin{tabular}{lc}
\hline $5^{\text {as }}$ séries escola da região periférica & $34,10 \%$ \\
$5^{\text {as }}$ séries escola da região central & "eu me senti triste" \\
& $26,50 \%$ \\
$8^{\text {as }}$ séries escola da região periférica & "eu me senti triste" \\
& $29,80 \%$ \\
$8^{\text {as }}$ séries escola da região central & "eu me senti mal" \\
& $28,40 \%$ \\
Ambas as escolas & "eu me senti mal" \\
& $29,60 \%$
\end{tabular}

Nota. Fonte: Pesquisa de Campo, 2006 - Nível de significância < 0,05.

$\mathrm{Na}$ análise relativa às reações que tiveram os alunos quando maltratados na escola (Tabela 5), percebeu-se que $33,00 \%$ dos alunos das $5^{\text {as }}$ séries da escola localizada na região periférica disseram ter se defendido dos maus tratos, enquanto que na escola localizada na região central o percentual deste item foi de $18,40 \%$, entretanto, o que prevaleceu foi o percentual de $24,50 \%$ dos que ressaltaram ter pedido ajuda a um adulto, enquanto que na escola localizada na região periférica, o percentual para este item foi de $11,40 \%$. O teste Qui-quadrado no que se refere à resposta "Me defendi" apresentou $p$-valor igual a 0,06 para as $5^{\text {as }}$ séries de ambas as escolas, ou seja, não há diferença significativa. Entretanto, para a resposta "Pedi ajuda a um adulto", apresentou-se um $p$-valor de 0,04, ou seja, nesse caso há diferença estatística significativa entre as $5^{\text {as }}$ séries.

Nas $8^{\text {as }}$ séries notou-se a preferência pela resposta, "não dei atenção, ignorei-os", com percentual de $26,20 \%$ para a escola localizada na região periférica e $28,40 \%$ para a escola da região central. O teste Qui-quadrado apresentou $p$-valor igual a 0,74 para as $8^{\text {as }}$ séries das escolas das duas regiões, o que indica não haver diferenças significativas entre ambas.

Os alunos das $5^{\text {as }}$ séries demonstraram distintas formas de enfrentamento aos maus tratos sofridos, quando comparados aos alunos de $8^{\text {as }}$ séries, na medida em que os menores apresentam uma atividade mais ativa, em detrimento de uma postura mais passiva de não reação explícita, presente nas respostas dos alunos de $8^{\text {as }}$ séries.

Em Martins (2005) averiguou-se que a maioria dos jovens considera a possibilidade de contar com o auxílio dos professores para resolver os problemas de maus tratos, além de considerarem que a maioria dos professores parecem preocupados com esse tipo de problemas, mas que muitos não se encontram preparados ou não sabem como impedi-los.

Tabela 5

Reações de Alunos aos Maus Tratos na Escola

Reações de alunos quando maltratados na escola

\begin{tabular}{ll}
\hline $5^{\text {as }}$ séries escola da região periférica & $33,00 \%$ \\
& "eu me defendi" \\
$5^{\text {as }}$ séries escola da região central & $24,50 \%$ \\
& "pedi ajuda a um adulto" \\
$8^{\text {as }}$ séries escola da região periférica & $26,20 \%$ \\
& "não dei atenção, ignorei-os" \\
$8^{\text {as }}$ séries escola da região central & $28,40 \%$ \\
& "não dei atenção, ignorei-os" \\
Ambas as escolas & $23,30 \%$ \\
& "não dei atenção, ignorei-os"
\end{tabular}

Nota. Fonte: Pesquisa de Campo, 2006 - Nível de significância < 0,05. 
Em uma das questões abertas contidas no questionário, que visou identificar a opinião dos alunos sobre o que poderia ou deveria ser feito para ajudar quem sofre maus tratos na escola, após o agrupamento das respostas em categorias de análise constatou-se que, na escola da região periférica, $16,70 \%$ dos alunos acreditam que falar com a direção, inspetores, pais, professores e a polícia seria suficiente para ajudar as vítimas. Já $11,30 \%$ dos alunos apontaram que expulsar o agressor da escola resolveria o problema, e 6,60\% ressaltaram que a direção e os funcionários deveriam ser mais atentos com os maus tratos. $\mathrm{Na}$ escola da região central, 30,60\% acreditam que expulsar os agressores seria o suficiente; $10,70 \%$ não sabem o que fazer para ajudar as vítimas e 5,80\% destacaram que punir os agressores seria aceitável. Vale enfatizar que na escola da área central, onde se supõe não haver continuidade no relacionamento entre os alunos após o horário escolar, $30,60 \%$ optaram pela exclusão daquilo que causa o problema, fato mencionado por apenas $11,30 \%$ dos estudantes da outra instituição.

Para as freqüências sobre a expulsão dos agressores como medida eficaz para a resolução dos problemas, o teste $Q u i$ quadrado apresentou $p$-valor de 0,00 , ou seja, há diferença significativa entre ambas as escolas. Nos demais questionários das duas escolas percebeu-se respostas bem distintas e que não possibilitaram o seu agrupamento.

Abaixo seguem algumas respostas ilustrativas da amostra à seguinte questão: "O que você acha que poderia ou deveria ser feito para ajudar quem sofre os maus tratos na escola?".

"Depois do que aconteceu comigo eu acho que nada, falei com professores, diretores, amigos e nada mudou. Ontem me maltrataram na sala de aula. Só basta rezar e mais nada."

"Dar suspensão, mas no meu caso preferia que os agressores saíssem da escola."

"Contar para a direção ou professores."

"Nem sei, porque não adianta nada."

"Os filhos deveriam falar para os seus pais sobre os maus tratos."

Muitos alunos apresentam dificuldades em resolver as diversas situações de violência, ao propor soluções momentâneas de combate ao bullying. No entanto, deve ser levado em consideração que tais alunos estão em processo de desenvolvimento e construindo recursos para lidar com as diversas situações.

Outro aspecto que merece atenção, diz respeito aos alunos que, após terem tentado ajuda junto aos profissionais da escola, e verificarem que tiveram dificuldades em auxiliá-los, não vêem mais alternativas para resolver este problema. Tais dificuldades não estão ligadas somente ao descaso em resolver os conflitos, mas supõe-se que haja falta de informações e recursos para os profissionais da educação lidar com as distintas formas de violência. Daí a importância de trazer as discussões sobre tal assunto para o meio acadêmico, escolar e demais segmentos sociais, afim de que avanços e respostas possam ser oferecidos a toda sociedade.

\section{Considerações Finais}

Acredita-se que as reflexões do presente trabalho possam subsidiar a elaboração de campanhas e projetos em âmbito escolar, que se voltem ao enfrentamento do bullying. Martins (2005) enfatiza que os programas de prevenção da violência escolar devam dirigir-se mais aos grupos (escolas e turmas), do que aos indivíduos especificamente, e que o fato de se manifestar sob diferentes formas, sugere que as estratégias de intervenção ou prevenção deverão levar em conta o tipo de bullying que se pretenda prevenir ou erradicar.

Ao analisar a quem os alunos recorrem quando maltratados na escola, percebe-se então que, boa parte busca o auxílio dos pais e professores. É fato que o bullying se faz presente nas escolas e que muitas vezes estes casos de violência estão tão bem camuflados que ninguém consegue identificá-los e media-los; ou as pessoas vêem e preferem não tomar parte, ou até mesmo, não se sentem preparadas para tal, inclusive os professores, justificando a necessidade de maiores debates na área da educação visando uma conscientização sobre os efeitos do bullying, os quais não ficam restritos às vítimas, agressores e espectadores, mas à sociedade de uma forma geral.

Gomes et al. (2007) elucidam que o fenômeno permanece tão oculto na maioria das vezes, que poderia ser denominado de "ponta de iceberg", visto que, o que se denuncia é apenas um pálido reflexo da realidade, quando a maior parte permanece invisível.

Pereira (2002) aponta que as vítimas, frequentemente, não estão em posição de se defender ou procurar auxílio e que na maioria das vezes se calam por medo de se expor perante os outros. Há um ponto, então, que merece atenção: aqueles que sofrem bullying e não falam com ninguém, apesar de terem sido maltratados. Isso vem confirmar as dificuldades que muitas crianças e adolescentes têm para lidar ou enfrentar a violência que sofrem no interior da escola.

Nesse sentido, aponta-se para a necessidade da realização de pesquisas que busquem compreender se a ausência ou dificuldade de relações sociais em ambientes não escolares favorece a ocorrência de violência entre pares. Torna-se necessário ainda pensar em que medida os aspectos culturais e sociais podem interferir na produção do bullying. Almeida et. al. (2007) e Lopes Neto (2005) ilustram que os maus tratos entre escolares por mais que ocorram em um mesmo ambiente, no qual se possa identificar vítimas, agressores ou telespectadores, deve-se considerar que diferentes narrativas serão geradas de acordo com a experiência, os papéis sociais e práticas modeladas pela cultura dos sujeitos.

Convém salientar que diante de todas as suas limitações, este estudo não teve a pretensão de esgotar as discussões sobre o bullying e, sim de contribuir para dar-lhe visibilidade no meio acadêmico e escolar, bem como auxiliar na elaboração de projetos que se voltem ao enfrentamento do bullying. Autores como Lopes Neto (2005) e Mascarenhas (2006) explanam que tais projetos devem envolver profes- 
sores, funcionários, pais e alunos, de modo que a participação de todos assegure estabelecer normas, diretrizes e ações coerentes. Tais ações visam promover vivências, debates e conscientização geral, além de explicitar valores fundamentais de respeito mútuo, solidariedade e diálogo, durante todos os momentos da vida escolar. Vale apontar que cada escola deve ser vista como única, e que as estratégias a serem desenvolvidas devem considerar sempre as características sociais, econômicas e culturais de sua população.

\section{Referências}

Abramovay, M. (Ed.). (2003). Escola e violência (2. ed.). Brasília, DF: UNESCO.

Almeida, A., Lisboa, C., \& Caurcel, M. J. (2007). ¿Por qué ocurren los malos tratos entre iguales? Explicaciones causales de adolescentes portugueses y brasileños. Revista Interamericana de Psicologia, 41(2), 107-118.

Debarbieux, E., \& Blaya, C. (Eds.). (2002). Violência nas escolas e políticas públicas. Brasília, DF: UNESCO.

Donnon, T., \& Hammond, W. (2007). Understanding the relationship between resiliency and bullying in adolescence: An assessment of youth resiliency from five urban high schools. Child and Adolescence Psychiatric Clinics of North America, 16, 449-471.

Elliott, M. (1992). Bullying: A practical guide to coping for schools. Harlow, UK: BPC Wheatons.

Fante, C. A. Z. (2003). Fenômeno bullying: Estratégias de intervenção e prevenção entre escolares (uma proposta de educar para a paz). São José do Rio Preto, SP: Ativa.

Fante, C. A. Z. (2005). Fenômeno bullying: Como prevenir a violência nas escolas e educar para a paz. Campinas, SP: Verus.

Freire, I. P., Simão, A. M. V., \& Ferreira, A. S. (2006). O estudo da violência entre pares no $3^{\circ}$ ciclo do ensino básico: Um questionário aferido para a população portuguesa. Revista Portuguesa de Educação, 19(2), 157-183.

Gomes, A., Gala, F. J., Lupiani, M., Bernalte, A., Miret, M. T., Lupiani, S., et al. (2007). El bullying y otras formas de violência adolescente. Cuadernos de Medicina Forense, 13(48/49), 165-177.

Gouveia, A. J. (1984). Notas a respeito das diferentes propostas metodológicas apresentadas. Cadernos de Pesquisa (São Paulo), 49, 67-70.

Lopes Neto, A. A. (2005). Bullying: Comportamento agressivo entre estudantes. Jornal de Pediatria (Rio de Janeiro), 81(5), 164-172.

Martins, M. J. D. (2005). Agressão e vitimação entre adolescentes em contexto escolar: Um estudo empírico. Análise Psicológica, 4(23), 401-425.

Mascarenhas, S. (2006). Gestão do bullying e da indisciplina e qualidade do bem-estar psicossocial de docentes e discentes do Brasil (Rondônia). Psicologia, Saúde \& Doenças, 7(1), 95107.

Olweus, D. (1991). Bully/victim problems among schoolchildren: Basic factors and effects of a school-based intervention program. Hillsdale, NJ: Erlbaum.

Ortega, R., \& Del Rey, R. (2002). Estratégias educativas para a prevenção da violência. Brasília, DF: UNESCO.

Palácios, M., \& Rego, S. (2006). Bullying: Mais uma epidemia invisível?. Revista Brasileira de Educação Médica, 30(1), 3-5.
Pereira, B. O. (2002). Para uma escola sem violência: Estudo e prevenção das práticas agressivas entre crianças. Porto, Portugal: Imprensa Portuguesa.

Pizarro, H. C., \& Jiménez, M. I. (2007). Maltrato entre iguales en la escuela costarricense. Revista Educación, 31(1), 135144.

Ramírez, F. C. (2001). Variables de personalidade asociadas en la dinámica bullying (agresores versus víctimas) en niños y niñas de 10 a 15 años. Anales de Psicologia, 17(1), 37-43.

Thiollent, M. J. M. (1984). Aspectos qualitativos da metodologia de pesquisa com objetivos de descrição, avaliação e reconstrução. Cadernos de Pesquisa (São Paulo), 49, 45-50.

Tognetta, L. R. P. (2005). Violência na escola: Os sinais de bullying e o olhar necessário aos sentimentos. In A. Pontes \& V. S. Lima (Eds.), Construindo saberes em educação (pp. 1132). Porto Alegre, RS: Zouck.

Valles, R. Q., Jr. (2007). How succesful high school students cope with bullying: A qualitative study. Unpublished doctoral dissertation, Faculty of the Rossier School, Education University of Southern California, Los Angeles, CA.
Recebido: 04/04/2008

$1^{a}$ revisão: $22 / 07 / 2008$ $2^{a}$ revisão: $12 / 09 / 2008$ Aceite final: $02 / 10 / 2008$ 